\title{
Proceeding
}

Supplementary Issue: Spring Conferences of Sports Science. 15th Convention and Workshop of the International Network of Sport and Health Science, 5-8 June 2019. University of Las Palmas de Gran Canaria, Las Palmas de Gran Canaria, Spain.

\section{Self-perception about health and wellness effects on recreational five-a-side football athletes}

\author{
NICOLA CHRISTIAN SEVERINO ${ }^{1}$, FRANCESCO PELUSO CASSESE², RICCARDO IZZO³ , ILARIA \\ VISCIONE ${ }^{1}$ \\ 1 University of Salerno, Italy \\ 2University Niccolò Cusano of Rome, Italy \\ 3 University Carlo Bo of Urbino, Italy
}

\begin{abstract}
In this study, we examine the health and well-being perceptions arising from some of the most commonly used physical activities to achieve physical well-being. In particular, we focus on the perceptive aspects specific to recreational football, trying to understand what can be the parameters that acquire a greater benefit on a physical level and what are the diseases that can be prevented by practicing this activity. Through some questions asked to a group of 15 boys, aged between 23 and 29, it was found that recreational football can achieve greater physical resistance $(71.4 \%)$ and a decrease in body fat $(57.1 \%)$, and that we can prevent cardiovascular diseases $(76.9 \%)$ and obesity $(61.5 \%)$. Furthermore, the data collected showed that the analysed sample considers it more appropriate to do the one activity than another, depending on the physical well-being that one wants to achieve. For example, according to the interviewees, to increase lean mass it is better to perform strength training (66.7\%). According to many other studies, therefore, this type of activity significantly improves both in terms of perceptions and real data, the general physical well-being of the person who practices it. Keywords: Google form drive; Well-being; Strength training; Interval Running.
\end{abstract}

Cite this article as:

Severino, N.C., Cassese, F.P., Izzo, R., \& Viscione, I. (2019). Self-perception about health and wellness effects on recreational five-a-side football athletes. Journal of Human Sport and Exercise, 14(4proc), S797-S804. doi:https://doi.org/10.14198/ihse.2019.14.Proc4.42

Corresponding author. University of Salerno, Italy.

E-mail: n.severino3@studenti.unisa.it

Supplementary Issue: Spring Conferences of Sports Science. 15th Convention and Workshop of the International Network of Sport and Health Science, 5-8 June 2019. University of Las Palmas de Gran Canaria, Las Palmas de Gran Canaria, Spain. JOURNAL OF HUMAN SPORT \& EXERCISE ISSN 1988-5202

(c) Faculty of Education. University of Alicante

doi:10.14198/jhse.2019.14.Proc4.42 


\section{INTRODUCTION}

Exercise and sport sciences field is very widely and is investigated under several performance approaches (D'elia, 2019, D'Isanto, 2019, Raiola et al, 2018, Sanseviero et al, 2019) but it is developing health and wellness applications (Gaetano, 2016, Tiziana et al, 2017, Severino etal, 2019). There are researches carried out on specific sports, aimed at demonstrating what improvements can come from its practice (Ceruso et al, 2019, Giordano et al, 2019). According to Raiola (Raiola, 2017, 2015ab, 2013, Raiola, Di Tore, 2017) about the psych-physical benefits for several sports, such as volleyball, basketball and football, it has shown the relationship in helping the body and mind (Ceciliani, 2019, Ceciliani et al, 2005, Valentini et al, 2018) to reach maximum strengths and motor coordination and so, performance efficacy. As following, Kustrup has shown (Kustrup, Kustrup, 2018, Kustrup et al, 2010), through numerous studies over time, the effectiveness of recreational football is improving VO2 max, muscle and bone mass of the legs and lowering the blood pressure, such as the high performance (Altavilla et al, 2018ab, D'Isanto et al, 2019, Raiola, D'isanto, 2017), and without fraudulent practice (Mazzeo et al, 2018ab). In summary, we can say that sport helps to improve health through processes that entail improvements in various body components. The aim of this study is to assess the health and well-being perceptions arising from some of the most commonly used physical activities to achieve physical well-being, including strength training (gym training) or jogging. In particular, we focus on the perceptive aspects of the recreational football, trying to understand which can be the parameters that acquire a greater benefit on a physical level and which are the diseases that can be prevented by practicing this kind of activity.

\section{METHOD}

Method is experimental by quali/quantitative approach by a questionnaire with google form drive. A random sample of five-a-side football players was examined, in particular they were 15 male boys, all of them declared to practice recreational football during the period of the research. $13.3 \%$ of them have practiced competitive football in the past, as for the attendance, $80 \%$ of them regularly practice recreational football, while $20 \%$ of them practice low-frequency football. As regards the collection of information, it was decided to undertake a quantitative approach by adopting a structured questionnaire as a survey tool, which was based on the objectives the study intended to reach. All the questions in the questionnaire are closed-ended, in some cases multiple answers could be chosen simultaneously, to try to form a sort of ranking with the answers given by the subjects. The questionnaire was prepared with Google Forms, an online platform that allows you to build these types of tests in a very simple way through standardized interviews. The questionnaire was sent to the interviewees, who were able to complete it and later send the answers anonymously, where all the information was collected in the form of graphs using spreadsheets. The definitive questionnaire consists of two main parts: in the first part, we investigate the perceptions and knowledge concerning the benefits of recreational football and whether it can be a prevention for some diseases. In the second part, we investigate the perceptions and knowledge relating to a group of sports used to achieve physical well-being. The answers have been revised in percentage to make the results easier to use, so as to allow an easier discussion with more direct conclusions.

\section{RESULTS}

In the first question of the first part, it was asked if "they knew the benefits of recreational amateur football" and $93.3 \%$ of them answered positively, while just one of the 15 participants said he did not know the benefits. 
To those who answered in the affirmative, they were later asked to choose "which, among the benefits indicated, they considered have originated from the activity of recreational football". This question gave the opportunity to choose between multiple answers, so that some benefits were selected more than others, creating a sort of ranking.

As mentioned, the participants who answered were 14 because one person said he did not know the benefits. The most selected answer was "Increase in physical endurance" with 10 selections out of 14 (71.4\% of the participants), and it is exactly the parameter that I tried to evaluate in the tests carried out in the first experimental part. Immediately after, there are the answers "Decrease in body fat" with 8 selections out of $14(57.1 \%)$ and "Increase in movements mobility and speed" with 7 selections out of $14(50 \%)$. Lastly, we have the answer "Increase in muscle and bone mass" which was selected 3 times out of $14(21.4 \%)$ and "Decrease in blood pressure" which was chosen only once by the 14 participants (6.7\%), (Figure 1).

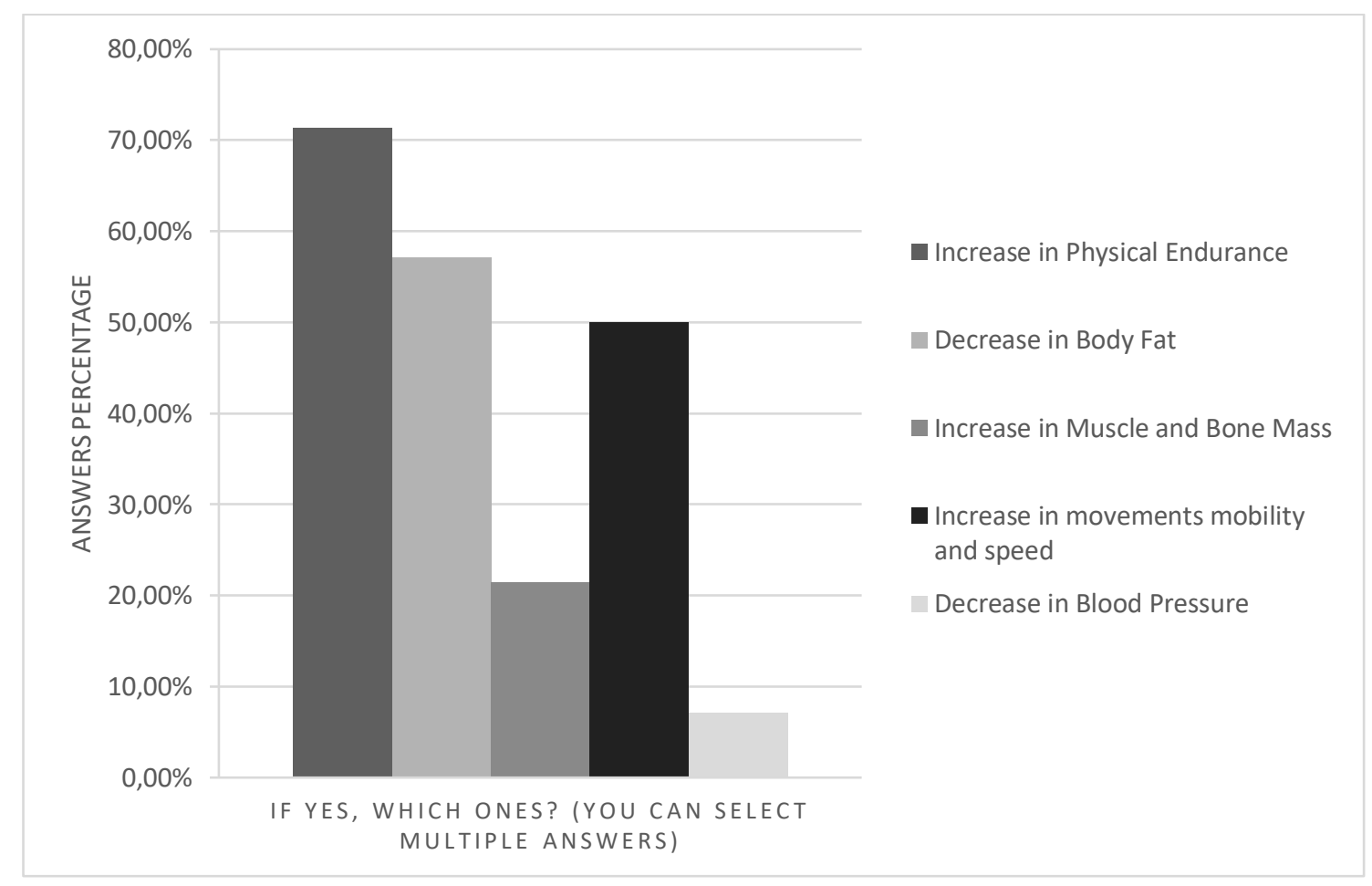

Figure 1. Participant answers $A$.

Later, it was asked, "if recreational amateur soccer is also considered a health prevention". $86.7 \%$ of the participants answered in the affirmative, while 2 participants out of 15 responded negatively $(13.3 \%)$.

In the next question was then asked, "for what kind of disease this activity they think could be a prevention" and the participants could choose between more answers, to recreate a sort of ranking as it has been done previously.

Two of the participants have responded negatively to the previous question, therefore they did not answer to this question, since they do not believe that it can be a health prevention in practising this type of activity. 
The most frequently selected response was "General well-being", 11 times out of $13(84.6 \%)$ since it is widely known that practising this physical activity is good for the general well-being, and it helps to prevent some kind of diseases. In particular, since they had to choose between different types of diseases, the participants selected mostly "Cardiovascular diseases", 10 out of $13(76.9 \%)$ and "Obesity" selected 8 times out of 13 $(61.5 \%)$. While "Risk of fractures" and "Diabetes" were both selected once out of 13 responses $(6.7 \%)$, since the participants thought that these diseases, among those indicated, were more difficult to prevent by practising the activity of recreational football, (Figure 2).

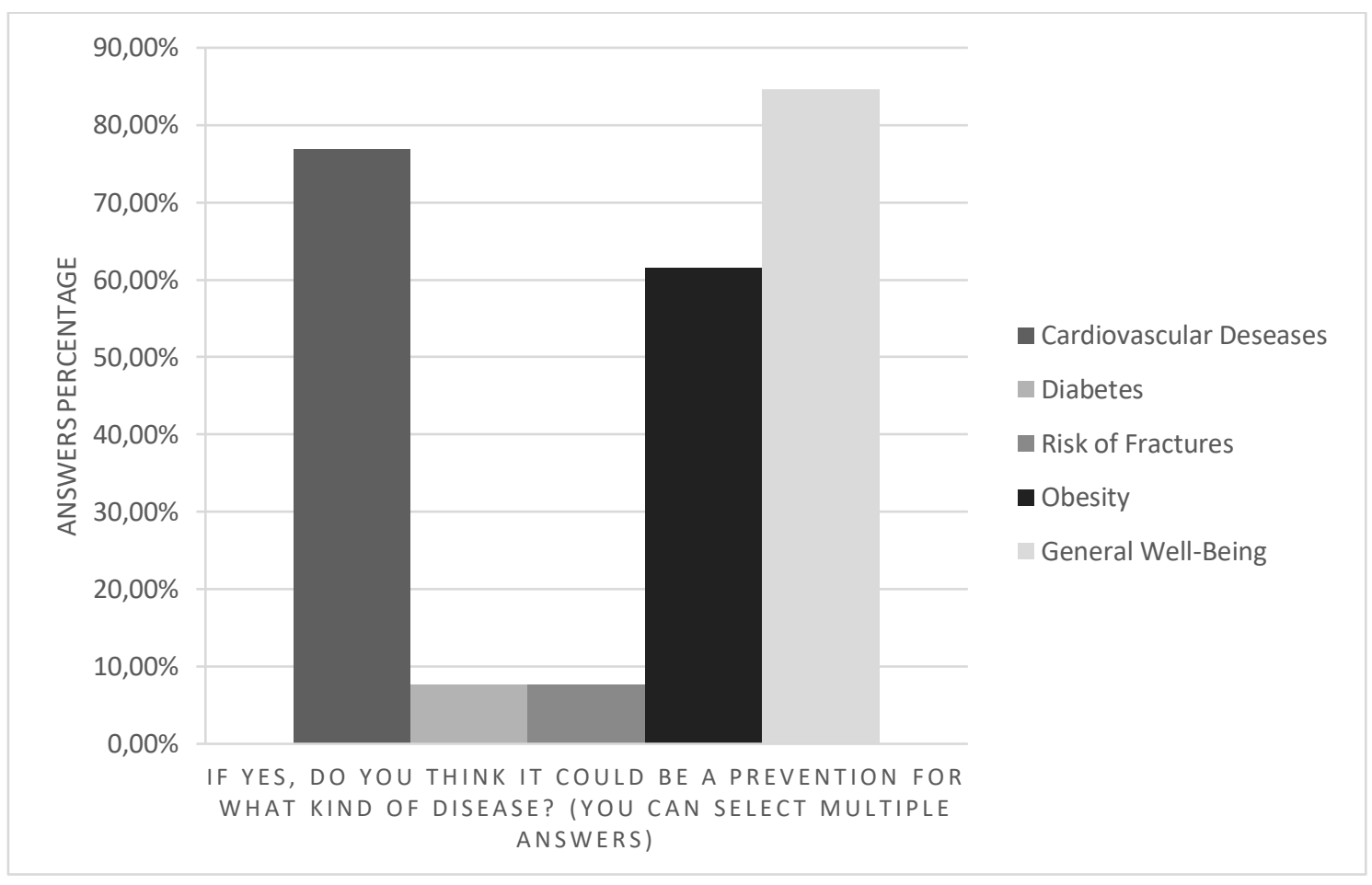

Figure 2. Participant answers B.

In the next part, a series of questions asked the participants to identify, according to their perception and knowledge, the most effective activity in providing the benefit indicated in the question itself. In the first question of this group, it was asked "which sport, among those indicated, they think will have the greatest influence on the decrease in body fat percentage" and with the highest percentage, $46.7 \%$, "Interval Running" turned out to be the main choice. Immediately after we find the "Jogging" with $26.7 \%$ and the "Recreational Football" with $20 \%$ of the answers. Finally, we have "Strength training" which was selected only once with $6.7 \%$, and the "Core control" which was not selected.

Later, it was asked, "which of the activities indicated should be considered, according to one's own knowledge, most influential as regards the increase in lean mass". The majority of the participants indicated "Strength training" (66.7\%), followed by "Recreational football" (20\%). "Interval Running" and "Jogging" were both selected once ( $6.7 \%$ each), while the "Core Control" was not selected.

Instead to the question, "according to your perception, which of these sports do you think will have the greatest influence on the increase in the bone mass of the legs?", the main response was "Interval Running" 
with 46.7\%, immediately after we find "Strength Training" with 33.3\% and "Jogging" with $13.3 \%$. Only one person selected "Recreational Football" (6.7\%) and no one selected "Core Control".

In the last question, it was asked "according to your perception, which of these sports do you think will have the greatest influence on the increase in physical endurance" and the response rates were: $60 \%$ for "Interval Running", while "Jogging" and " Recreational football" both have had $20 \%$ of the answers. "Strength training" and "Core control" were not selected, (Figure 3).

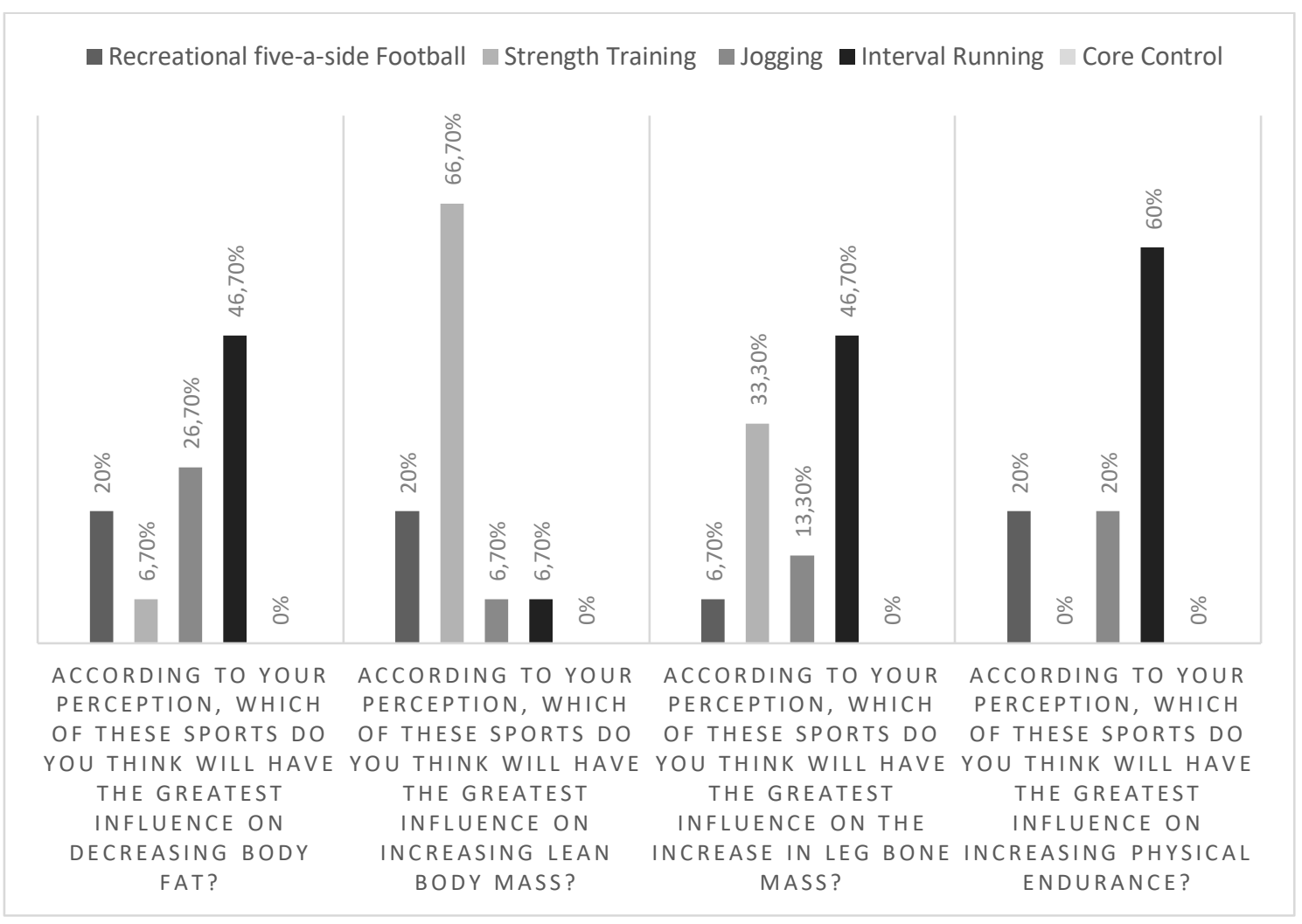

Figure 3. Comparison participant answers.

Table 1. Statistical table

\begin{tabular}{|l|l|l|}
\hline Chi Square Test & & \\
\hline Chi-square (observed value) & 4 & \\
\hline Chi-square (critical value) & 17 & \\
\hline GDL & 9 & \\
\hline$p$-value & 1 & 0.05 \\
\hline alpha & & \\
\hline Interpretation: & \\
$\mathrm{H}_{0}:$ the lines and the columns of the table are independent from each other. & \\
$\mathrm{H}_{1}:$ There is a dependent between the two taking into consideration that the calculated $\mathrm{p}$-value is greater \\
than the level of alpha threshold. it isn't possible to reject the null hypothesis $\mathrm{H}_{0}$. \\
\hline
\end{tabular}




\begin{tabular}{|l|l|l|}
\hline Association coefficients: & Value & \\
\hline Phi of Pearson & 0.250789998 & \\
\hline Contingency table: & Value & SD \\
\hline Gamma di Goodman e Kruskal & 0.06746988 & 0.16 \\
\hline
\end{tabular}

Table 2. Graduated answers

\begin{tabular}{|l|c|c|c|c|}
\cline { 2 - 5 } \multicolumn{1}{c|}{} & Question 1 & Question 2 & Question 3 & Question 4 \\
\hline Level A & 7 & 10 & 7 & 9 \\
\hline Level B & 4 & 3 & 5 & 3 \\
\hline Level C & 3 & 1 & 2 & 3 \\
\hline Level D & 1 & 1 & 1 & 0 \\
\hline
\end{tabular}

\section{DISCUSSION}

The data found showed that, even in terms of perceptions and knowledge, recreational football can bring benefits, improving some physical parameters fundamental to the well-being. In fact, analysing the data related to these improvements, it is evident that the most selected benefits are the "most visible" ones, that is those that have a greater impact on the participants and a change that is easier to perceive. For instance, we have a decrease in body fat, which is obvious and can be verified with tools that are easy to find and easy to use. Or we have a greatest agility and rapidity of movements and the increase in physical resistance, which are easily perceived physical characteristics and therefore with even a minimal change, we are easily aware of the variation. Conversely, the increase in the muscle and bone mass and the decrease in blood pressure are transformations that do not have a clearly visible and rapidly verifiable proof, except through special instruments. And yet, among the most important variations illustrated in the studies of prof. Kustrup, we find a decrease in arterial pressure and an increase in bone mass, especially in the lower limbs.

Furthermore, it was found that, even at a perceptive level, recreational football is considered by the subjects examined to be a preventive sport for some lifestyle-related diseases, such as cardiovascular diseases and obesity, as well as a fundamental activity for improving general well-being.

As for the perceptions and knowledge relating to other types of activities, it was found that the subjects are aware that each activity may have a different influence on various parts of the body and therefore they indicate a different sport depending on the improvements that can be more found.

\section{CONCLUSIONS}

In conclusion, it can be stated that the perceptions of health and well-being of the research subjects, arising from some of the most commonly used physical activities to reach physical well-being, such as strength training or light running, are considered specific for a given physical parameter. In fact, the subjects believe that it is better to use strength training to improve lean mass, while it is better to undertake an interval running to decrease the percentage of body fat. On the other hand, focusing on recreational football, it can be said that subjects believe that it is a sport that can bring complete benefits, both by improving physical endurance and agility of movement and by decreasing body fat. Moreover, it was also considered by the subjects a prevention sport capable of counteracting some of the most harmful lifestyle-related diseases, such as cardiovascular diseases and obesity, and improving the general well-being of the person.

\section{REFERENCES}


Altavilla, G., D'Elia, F., Raiola, G. (2018a) A brief review of the effects of physical activity in subjects with cardiovascular disease: An interpretative key, Sport Mont, 16 (3), 103-106.

Altavilla, G., Mazzeo, F., D'Elia, F., Raiola, G. (2018b) Physical commitment and specific work for each role in an elite soccer team, Journal of Physical Education and Sport, 18 (2), 570-574.

Ceciliani, A. (2018)From the embodied cognition to the embodied education in the physical and sports sciences, Encyclopaideia, 22 (51), pp. 11-24.

Ceciliani, A., Di Carlo, M., Tentoni, C. (2005) Mental process learning Medicina dello Sport, 58 (1), pp. 43-52.

Ceruso, R., Esposito, G., Federici, A., Valentini, M., D'isanto, T., Preliminary work about the basis data for monitoring youth soccer team planning training(2019) Journal of Human Sport and Exercise, 14 (Proc2), pp. S251-S257. https://doi.org/10.14198/jhse.2019.14.proc2.14

D‘Elia, F. (2019). The training of physical education teacher in primary school. Journal of Human Sport and Exercise, 14(1proc), S100-S104. https://doi.org/10.14198//hse.2019.14.Proc1.12

D'Elia, F., Mazzeo, F., Raiola, G. (2018) The core curriculum in the university training of the teacher of physical education in Italy, Journal of Human Sport and Exercise, 13, pp. S413-S420. https://doi.org/10.14198/ihse.2018.13.proc2.25

D'Isanto, T., D'Elia, F., Raiola, G., Altavilla, G. (2019)Assessment of sport performance: Theoretical aspects and practical indications, Sport Mont, 17 (1), pp. 79-82.

D'isanto, T. (2019) Physical and sport education between Italian academic system and European Research Council structure panel, Journal of Human Sport and Exercise, 14, pp. S66-S76. https://doi.org/10.14198//hse.2019.14.proc1.08

Gaetano, A. (2016) Relationship between physical inactivity and effects on individual health status, Journal of Physical Education and Sport, 16, pp. 1069-1074.

Giordano, L., Federici, A., Valentini, M., D'elia, F. (2019) Dribbling in football: Confronting learning theories, Journal of Human Sport and Exercise, 14 (Proc2), pp. S228-S232. https://doi.org/10.14198/ihse.2019.14.proc2.10

Krustrup, P., Krustrup, B.R. (2018) Football is medicine: It is time for patients to play! British Journal of Sports Medicine, 52 (22), pp. 1412-1413. https://doi.org/10.1136/bjsports-2018-099377

Krustrup P, Aagaard P, Nybo L, Petersen J, Mohr M, Bangsbo J, (2010) Recreational football as a health promoting activity: a topical review, Scand J Med Sci Sports, 20 (Suppl. 1): 1-13. https://doi.org/10.1111/j.1600-0838.2010.01108.x

Mazzeo, F., Altavilla, G., D'elia, F., Raiola, G. (2018a) Development of doping in sports: Overview and analysis, Journal of Physical Education and Sport, 18 (3), pp. 1669-1677.

Mazzeo, F., D'elia, F., Raiola, G. (2018b) Drugs in sport: Doping development and ethical analysis, Sport Science, 11 (1), pp. 106-112.

Raiola, G., D'elia, F., Altavilla, G. (2018) Physical activity and sports sciences between European Research Council and academic disciplines in Italy, Journal of Human Sport and Exercise, 13, pp. S283-S295. https://doi.org/10.14198/jhse.2018.13.proc2.13

Raiola, G. (2017) Motor learning and teaching method, Journal of Physical Education and Sport, 17, art. no. 236, pp. 2239-2243.

Raiola, G. (2013) Body knowledge and motor skills, Knowledge Cultures, 1 (6), pp. 64-72.

Raiola, G., Di Tore, P.A. (2017) Motor learning in sports science: Different theoretical frameworks for different teaching methods, Sport Science, 10, pp. 50-56.

Raiola, G., D'isanto, T. (2016) Assessment of periodization training in soccer, Journal of Human Sport and Exercise, 11 (Proc1), pp. S267-S278. https://doi.org/10.14198/jhse.2016.11.proc1.19 
Raiola, G. (2015a) Sport skills and mental health, Journal of Human Sport and Exercise, 10 (Proc1), 369376. https://doi.org/ihse.2015.10.Proc1.27

Raiola, G. (2015b) Inclusion in sport dance and self perception Sport Science, 8, pp. 99-102.

Sanseviero, I., Cassese, F.P., Fonzo, E., Altavilla, G., D'elia, F. (2019) Study on the master's degree in sciences of sports evaluation and sport for disabled at the University of Salerno, Italy, Journal of Human Sport and Exercise, 14 (Proc2), pp. S239-S244. https://doi.org/10.14198/ihse.2019.14.proc2.12

Severino, N.C., Cassese, F.P., Ceciliani, A., D'elia, F., Di Tore, A.P. (2019) Psychophysical benefits of recreational five-a-side football, Journal of Human Sport and Exercise, 14 (Proc2), pp. S206-S214. https://doi.org/10.14198/ihse.2019.14.proc2.07

Tiziana, D., Antonetta, M., Gaetano, A. (2017) Health and physical activity, Sport Science, 10 (1), pp. 100-105.

Valentini, M., Riccardi, F., Raiola, G., Federici, A. (2018) Educational research: Motor area and relational area during children's personality development, Journal of Physical Education and Sport, 18, art. no. 327 , pp. 2157-2174. 